\title{
Minimum of Two-Year Follow-up After Percutaneous Endoscopic Transforaminal Discectomy on Lumbar Disc Herniation: Clinical and Radiographic Outcomes
}

Lei Yue

Peking University First Hospital

Hao Chen

Peking University First Hospital

Guanzhang Mu

Peking University First Hospital

Bingxu Li

Peking University First Hospital

Haoyong Fu

Peking University First Hospital

Haolin Sun ( $\square$ sunhaolin@vip.163.com )

Peking University First Hospital

\section{Research Article}

Keywords: Percutaneous endoscopic transforaminal discectomy, minimally invasive, three-joint complex, spine surgery.

Posted Date: November 11th, 2021

DOI: https://doi.org/10.21203/rs.3.rs-1050709/v1

License: (ㄷ) (i) This work is licensed under a Creative Commons Attribution 4.0 International License. Read Full License 


\section{Abstract}

Background Percutaneous endoscopic transforaminal discectomy (PETD) is a widely-used minimally invasive technique in treating lumbar disc herniation (LDH), our aim was to investigate the long-term effect of PETD on clinical outcomes and magnetic resonance imaging (MRI) characteristics of LDH patients.

Methods This is a retrospective case series to assess patients who underwent single level PETD from January 2015 to June 2019 with a minimum follow-up of 2 years. Clinical outcomes included numeric rating scale (NRS), Oswestry Disability Index (ODI) and adverse events. Radiographic parameters included sagittal spine geometry, characteristics of protrusion, and degeneration grading of intervertebral disc and facet joint. Sensitivity analysis and risk factor analysis were also performed.

Results Thirty-eight patients ( $43.16 \pm 13.32$ years; $\mathrm{M}: \mathrm{F}=20$ : 18$)$ were assessed. During the follow-up period (33.47 \pm 12.53 months), the mean disc height decreased from $10.27 \pm 1.92 \mathrm{~mm}$ to $8.95 \pm 1.74 \mathrm{~mm}(\mathrm{P}=0.000)$, and lumbar lordosis increased from $31.31 \pm 8.63^{\circ}$ to $35.07 \pm 8.07^{\circ}(P=0.002)$. The size of protrusion significantly decreased after PETD $(P=0.000)$. Disc degeneration grading was generally higher at last follow-up compared with baseline $(p=0.002)$. Compared with baseline, significant improvements were observed on NRS and ODI at 3-months follow-up and the last follow-up. On risk factor analysis, facet tropism was correlated with radiographic recurrence of disc herniation (OR=6.00 [95\% confidential interval (CI)1.176-30.624], $\mathrm{p}=0.031)$.

Conclusions This study demonstrates that at long-term follow-up, despite the good clinical results, the PETD resulted in significant aggravation of intervertebral disc degeneration.

\section{Background}

The management of spinal disorders has been revolutionized by minimally invasive techniques, and the last three decades have witnessed a growing trend towards the widespread use of percutaneous endoscopic transforaminal discectomy (PETD) in treating lumbar disc herniation (LDH). Thanks to the development of operation systems and surgical techniques, indications of PETD have expanded; however, what comes along with the widespread use of PETD are surgical complications, including dural tear, infection, postoperative hypoesthesia, guidewire breakage and recurrent disc herniation[1]. To date, the current evidence may be insufficient in explaining the long-term effect of PETD due to short- to mid- term follow-up (i.e., less than 1 year) and lack of radiographic follow-up data.

Each lumbar motion segment is a three-joint complex, consisting of intervertebral disc (IVD) and two symmetric facet joints. Although percutaneous endoscopic techniques have achieved superior effects of minimizing approach-related trauma compared with traditional open lumbar procedures; however, evidence suggests that facetectomy in endoscopic surgery could lead to degeneration of both IVD and facet joint[2]. Unlike in percutaneous endoscopic interlaminar discectomy (PEID), facet joint is typically preserved in PETD, which facilitates observation of imaging changing process in lumbar three-joint complex after surgery[3]. The present study aims to provide evidence for the long-term effect of PETD, a facet joint damage-free technique, on LDH in terms of both radiographic and clinical aspects.

\section{Methods}

\section{Design}

This was a retrospective before and after study of patients undergoing PETD in a single academic medical center. The Institutional Review Board of Peking University First Hospital provided ethical approval for this study. 


\section{Participants}

We enrolled patients undergoing PETD for single level LDH. Patients were considered eligible on the ground of the following criteria: 18 years of age or older; diagnosed with LDH by a single senior spine surgeon of our institution, based on clinical manifestation, physical examination, and radiographical findings, and failure by conservative treatments; treated surgically with single level PETD; and finished a minimum follow-up of 24 months, after which MRI tests were performed. Patients were excluded based on the following: lumbar stenosis, spondylolisthesis, scoliosis, spinal trauma, ankylosing spondylitis, or spinal tumor; history of spine surgery; rheumatologic diseases; percutaneous endoscopic interlaminal discectomy (PEID); spinal implants; or intraoperative facetectomy or damage of facet joint.

\section{Surgical Procedure}

The PETD procedure was performed under spinal anesthesia with $6 \mathrm{~mL}$ of hypobaric ropivacaine (0.125\%). Then patient lay in prone position and surgical draping was performed on a routine basis. A puncture needle was introduced from the entry point, generally $8-13 \mathrm{~cm}$ from the midline, and placed in the disc space through Kambin's triangle. Then a guide wire was inserted through the puncture needle under the guidance of a fluoroscopic image, and then an 8-mm incision was made at the entry site. A cannulated obturator was inserted along the guide wire; after touching the ventral edge of the superior articular process, working cannula was inserted along the obturator and cannula position is ascertained by fluoroscopy. Foraminoplasty was performed if necessary. Next, endoscope equipment (TESSYS system; Joimax, Germany) was inserted through the cannula. The herniated disc and fibrotic scar tissues were removed using endoscopic forceps and ablation device (Trigger-Flex, Elliquence, USA). Annulus modulation was performed after the herniated fragment was completely removed, then the endoscope was removed and a sterile dressing was applied with a single stich suture. Figure 1 showed regional anatomy, the entry point choosing, puncture process of PETD.

\section{Outcomes Assessment}

- Radiographic measurements: Magnetic resonance imaging (MRI, 3T GE Discovery MR750 [Waukesha, WI, USA]) was used to determine the sagittal spine geometry, characteristics of herniated disc and degeneration grade of three-joint complex. All images were acquired with supine position in CTL-spine coil, FOV $=310 \mathrm{~mm}$ and 16-sagittal slices with $3 \mathrm{~mm}$ thickness. Sagittal spine geometry included intervertebral disc height (IDH), intervertebral disc angle (IDA), and lumbar lordosis (LL)[4]. Characteristics of herniated disc was assessed according to Michigan State University (MSU) classification system in terms of size and location of protrusion[5]. According to the recommendation by Kettler et, al., degeneration grade of three-joint complex included Pfirrmann grading system on sagittal T2W for disc degeneration, and Weishaupt grading system for facet joint degeneration[6-8]. The radiographic herniation recurrence was defined as the grade of MSU protrusion size at last follow-up to be no less than that of baseline. Figure 2 illustrates the above-mentioned grading methods. Special characteristics on MRI, i.e., Modic change and facet tropism, were assessed on baseline MRI screening according to previous criteria[9, 10], see Figure 3.

The MRI images were assessed in a blinded fashion by two independent trained observers (MGZ and FHY), who were blinded to the clinical and prior imaging results and measured the radiographic parameters with standardized methods. Numerical results of two raters were averaged. For grade variables, a consensus-based decision was adopted if there was a disagreement between the raters.

- Patient self-reported outcomes: Electronic medical records were retrospectively reviewed, baseline demographics, intraoperative data were collected. Patient self-reported outcomes was collected by a trained study coordinator (LBX), unaware of previous study details, by phone interview to assess the pain intensity (Numeric Rating Scale, NRS) and 
disability condition (Owestry Disability Index, ODI) of patients at baseline, at 3 months postoperatively and at last follow-up. Meanwhile, procedure-related adverse events, including infection, iatrogenic neurologic deficit, or additional surgeries was also collected within the time period of follow-up.

\section{Data analysis}

All data was de-identified and tabulated into an electronic spreadsheet (Microsoft, Redmond, WA) for statistical analysis. Univariable associations were tested by using chi-squared or Fisher's exact test for categorical variables, two-tailed paired t-test for normally distributed continuous variables, and Mann-Whitney $U$ test for non-normally distributed continuous variables. Risk analysis was performed on increased grading for degeneration of IVD and facet joint and radiographic reherniation by Chi-squared test and subsequent logistic regression. For clinical outcomes (NRS and ODI), sensitivity analysis was performed by stratification of variables age, gender, body mass index (BMI), and duration of symptoms. All numerical findings were presented with means \pm standard deviations (SDs). SPSS 27.0 (IBM, Armonk, NY) was used for statistical calculations, and results were considered statistically significant for $p$ values $<0.05$.

To determine the interobserver reliability for radiographic grading, i.e., Pfirrmann, MSU and Weishaupt grading, interobserver measurement agreement was assessed by weighted kappa analysis. Interpretation of numeric Kappa-values was described as $\mathrm{K} \leq 0.20$ as poor, $0.21-0.40$ as fair, $0.41-0.60$ as moderate, $0.61-0.80$ as good, and $0.81-1.00$ as very $\operatorname{good}[11]$.

\section{Results}

\section{Population}

During January 2015 to June 2019 in our hospital, data from 38 subjects who underwent single level PETD for LDH were finally included (Table 1). Mean follow-up period was 33.47 \pm 12.53 months. Among these patients, 14 patients experienced acute symptoms of less than 3 months and 24 patients experienced symptoms for at least 3 months. The operated disc space was mostly seen at L5/S1 (23 cases, 60.52\%), followed by L4/5 (13 cases, 34.21\%) and L3/4 (2 cases, $5.27 \%)$. The mean operation time was $98.32 \pm 32.15$ mins and mean hospital days was $3.74 \pm 2.85$ days. On baseline MRI screening, 9 individuals manifested Modic change and 9 individuals manifested facet tropism at the herniated space. 
Table 1

Demographic and clinical characteristics of enrolled participants $(\mathrm{N}=38)$

\begin{tabular}{|c|c|c|}
\hline & Mean & Standard deviation/Proportion \\
\hline Patients & 38 & \\
\hline Age (years) & 43.16 & 13.32 \\
\hline Body weight mass $\left(\mathrm{kg} \cdot \mathrm{m}^{2}\right)$ & 23.65 & 3.96 \\
\hline \multicolumn{3}{|l|}{ Gender } \\
\hline Female & 18 & $47.36 \%$ \\
\hline Male & 20 & $52.64 \%$ \\
\hline \multicolumn{3}{|l|}{ ASA scale } \\
\hline 1 & 14 & $36.84 \%$ \\
\hline 2 & 23 & $60.52 \%$ \\
\hline 3 & 1 & $2.64 \%$ \\
\hline \multicolumn{3}{|l|}{ Duration of symptoms } \\
\hline Acute & 14 & $36.84 \%$ \\
\hline Chronic & 24 & $63.16 \%$ \\
\hline \multicolumn{3}{|l|}{ Herniation space } \\
\hline $\mathrm{L} 3 / 4$ & 2 & $5.27 \%$ \\
\hline $\mathrm{L} 4 / 5$ & 13 & $34.21 \%$ \\
\hline L5/S1 & 23 & $60.52 \%$ \\
\hline \multicolumn{3}{|l|}{ Herniation location } \\
\hline A & 14 & $36.84 \%$ \\
\hline B & 18 & $47.36 \%$ \\
\hline C & 6 & $15.78 \%$ \\
\hline \multicolumn{3}{|l|}{ Modic change } \\
\hline Yes & 9 & $23.68 \%$ \\
\hline No & 29 & $76.32 \%$ \\
\hline \multicolumn{3}{|l|}{ Facet tropism } \\
\hline Yes & 9 & $23.68 \%$ \\
\hline No & 29 & $76.32 \%$ \\
\hline
\end{tabular}

\section{Radiographical Changes}

Radiographic changes were shown in Table 2. The IDH significantly decreased from $10.27 \pm 1.92 \mathrm{~mm}$ to $8.95 \pm 1.74 \mathrm{~mm}$ $(p=0.000)$. LL significantly increased from $31.31 \pm 8.63^{\circ}$ to $35.07 \pm 8.07^{\circ}(p=0.002)$. Pfirrmann grading were generally 
higher in last follow-up compared with baseline ( $p=0.002)$. MSU size grading was generally lower at final follow-up compared with pre-operatively $(p=0.000)$. Radiographic herniation recurrence was observed in 10 cases at the last followup. The interobserver agreements for the measured parameters were overall satisfactory, as kappa value for Pfirrmann grading was 0.818 , Weishaupt grading was 0.612 , and for MSU grading for size and location was 0.813 and 0.781 respectively.

Table 2

Change of postoperatively radiographic petameters compared with preoperatively after PETD $(\mathrm{N}=38)$.

\begin{tabular}{|llll|}
\hline & Preoperatively & Last follow-up & p-value \\
\hline IDH & $10.27 \pm 1.92$ & $8.95 \pm 1.74$ & 0.000 \\
\hline IDA & $7.25 \pm 5.87$ & $8.61 \pm 7.48$ & 0.080 \\
\hline LL & $31.31 \pm 8.63$ & $35.07 \pm 8.07$ & 0.002 \\
\hline Pfirrmann grading & & 0.002 \\
\hline 1 & 0 & 0 & \\
\hline 2 & 3 & 0 & \\
\hline 3 & 22 & 14 & \\
\hline 4 & 11 & 22 & \\
\hline 5 & 2 & 2 & \\
\hline Herniation size grading & & \\
\hline 1 & 0 & 18 & \\
\hline 2 & 20 & 18 & 0.669 \\
\hline 3 & 18 & 2 & \\
\hline Facet joint degeneration scale & 3 & \\
\hline 0 & 6 & 13 & \\
\hline 1 & 8 & 9 & \\
\hline 2 & 17 & 7 & \\
\hline 3 & 7 & & \\
\hline
\end{tabular}

On the risk factor analysis, the radiographical recurrence of disc herniation was correlated with facet tropism $(\mathrm{OR}=6.00$ [95\% confidential interval $(\mathrm{Cl}) 1.176-30.624], \mathrm{p}=0.031)$. No significant risk factors were found in aggravated degeneration of IVD or facet joint were noticed, for univariate analysis see Table 3. 
Table 3

Univariate risk factor analysis of aggravation of IVD, aggravation of facet joint, and radiographic reherniation.

\begin{tabular}{|c|c|c|c|c|c|c|c|c|c|}
\hline & \multicolumn{3}{|c|}{ Aggravation of IVD } & \multicolumn{3}{|c|}{ Aggravation of facet joint } & \multicolumn{3}{|c|}{ Radiographic reherniation } \\
\hline & Yes & No & & Yes & No & & Yes & No & \\
\hline \multicolumn{10}{|l|}{ Age } \\
\hline Above average & 8 & 8 & $p=0.511$ & 5 & 11 & $p=0.450$ & 5 & 11 & $p=0.713$ \\
\hline Below average & 8 & 14 & & 4 & 18 & & 5 & 17 & \\
\hline \multicolumn{10}{|l|}{ Gender } \\
\hline Male & 7 & 13 & $p=0.512$ & 2 & 18 & $p=0.058$ & 7 & 13 & $p=0.278$ \\
\hline Female & 9 & 9 & & 7 & 11 & & 3 & 15 & \\
\hline \multicolumn{10}{|l|}{$\mathrm{BMI}$} \\
\hline Above average & 4 & 13 & $p=0.052$ & 4 & 13 & $p=1.000$ & 6 & 11 & $p=0.293$ \\
\hline Below average & 12 & 9 & & 5 & 16 & & 4 & 17 & \\
\hline \multicolumn{10}{|c|}{ Symptom duration } \\
\hline$\geq 3 \mathrm{~m}$ & 10 & 14 & $p=1.000$ & 6 & 18 & $p=1.000$ & 8 & 16 & $p=0.268$ \\
\hline$<3 \mathrm{~m}$ & 6 & 8 & & 3 & 11 & & 2 & 12 & \\
\hline \multicolumn{10}{|l|}{ Modic change } \\
\hline Yes & 4 & 5 & $p=1.000$ & 4 & 5 & $p=0.174$ & 3 & 6 & $p=0.673$ \\
\hline No & 12 & 17 & & 5 & 24 & & 7 & 22 & \\
\hline \multicolumn{10}{|l|}{ Facet tropism } \\
\hline Yes & 4 & 5 & $p=1.000$ & 1 & 8 & $p=0.411$ & 5 & 4 & ${ }^{*} p=0.036$ \\
\hline No & 12 & 17 & & 8 & 21 & & 5 & 24 & \\
\hline
\end{tabular}

\section{Clinical Outcomes}

The changes in clinical outcomes were depicted in Figure 4. The baseline pain intensity score was $5.97 \pm 1.70$ while the baseline disability score was $56.9 \pm 18.00 \%$. At 3 months follow-up and the last follow-up, both NRS and ODI scores were significantly decreased comparing with baseline $(p=0.000)$. In contrast, no significant differences were observed between 3 months follow-up and the last follow-up. On sub-analysis when stratification of age, BMI, gender, symptom duration, no significant difference was noticed between subgroups. For adverse events, no patients reported infectious or iatrogenic neurologic deficit during the follow-up period. However, 4 patients required reoperation, in which 2 cases were reherniation (both at 2 years follow-up) in the operated segment and 2 cases suffered disc herniation at the adjacent segment (at 6 months follow-up and 4 years follow-up respectively).

\section{Discussion}


To date, only a handful of studies have investigated the long-term radiographical and clinical efficacy of PETD on $\mathrm{LDH}[12-15]$, which have been summarized in detail in Table 4. The current study analyzed the change of MRI parameters and self-reported outcomes in a minimum follow-up of 24 months before and after single level PETD. From the results, it is clear that the function significantly improved, IDH significantly decreased and the disc degeneration grade significantly increased in the current population. The changes of IDH, IVD degeneration grade and protrusion reduction are in

accordance with previous studies[12,14]. Although the facet joint degeneration grade aggravated in 9 patients, significant change in in facet joint degeneration was not found after PETD. To our knowledge, this is the first study to investigate the long-term effects of PETD on the changes both in clinical outcomes and MRI morphologic parameters of lumbar threejoint complex. 
Table 4

Summarize of literature of the long-term clinical and radiographic effects of percutaneous discectomy.

\begin{tabular}{|c|c|c|c|c|c|c|}
\hline Author year & Design & Popularion & Intervention & $\begin{array}{l}\text { Follow- } \\
\text { up } \\
\text { period }\end{array}$ & $\begin{array}{l}\text { Clinilcal } \\
\text { outcome }\end{array}$ & $\begin{array}{l}\text { Radiographic } \\
\text { outcome }\end{array}$ \\
\hline Lin et, al. 2021 & $\begin{array}{l}\text { Retrospective } \\
\text { case series } \\
(n=10)\end{array}$ & $\begin{array}{l}\text { Age: } 15.6 \\
(13-17) \\
\text { years-old } \\
\text { Gender: } 6 \\
\text { males vs. } \\
4 \text { females; }\end{array}$ & $\begin{array}{l}\text { Percutaneous } \\
\text { endoscopic } \\
\text { lumbar } \\
\text { discectomy }\end{array}$ & 1 year & $\begin{array}{l}\text { Baseline: } \\
\text { Back-pain } \\
\text { VAS: } 6.2 \\
\text { Leg VAS: } 6.9 \\
\text { ODI: } 20 \% \\
\text { Last follow- } \\
\text { up: } \\
\text { Back-pain } \\
\text { VAS: } 0.3 \\
\text { Leg VAS:0.5 } \\
\text { ODI: } 0.1 \%\end{array}$ & $\begin{array}{l}\text { The 1-year } \\
\text { post-operative } \\
\text { modified } \\
\text { Pfirrmann } \\
\text { grading was } \\
4.8 \pm 1.40 \\
\text { compared with } \\
3.0 \pm 1.05 \text { at } \\
\text { baseline } \\
\text { (p<0.05); } \\
\text { The disc height } \\
\text { change was } \\
\text { not } \\
\text { significantly } \\
\text { different. }\end{array}$ \\
\hline $\begin{array}{l}\text { Mahatthanatrakul } \\
\text { et, al. } 2019\end{array}$ & $\begin{array}{l}\text { Retrospective } \\
\text { case series } \\
(n=31)\end{array}$ & $\begin{array}{l}\text { Age: } 38.3 \\
\pm 14.4 \\
\text { years-old } \\
\text { Gender: } 23 \\
\text { males vs. } \\
8 \text { females. }\end{array}$ & PETD & 1 year & $\begin{array}{l}\text { First follow- } \\
\text { up: } \\
\text { Back-pain } \\
\text { VAS: } 2.0 \text { (1.0 } \\
\text { to 3.0) } \\
\text { Leg VAS: } 1.0 \\
\text { (1.0 to } 3.00) \\
\text { ODI: } 18.2 \% \\
\text { (12.7 to } \\
35.7 \%) \\
\text { Last follow- } \\
\text { up: } \\
\text { Back-pain } \\
\text { VAS: } 2.0 \text { (1.0 } \\
\text { to } 3.0) \\
\text { Leg VAS: } 1.0 \\
\text { (0.0 to } 2.0) \\
\text { ODI: } 12.7 \% \\
\text { (9.1 to } \\
17.8 \%)\end{array}$ & $\begin{array}{l}\text { Disc height at } \\
\text { last follow-up } \\
\text { was lost by } 8.4 \\
\pm 11.4 \% \\
\text { compared to } \\
\text { MRI at day } 1 \\
(p<0.001) ; \\
\text { Disc protrusion } \\
\text { size was } \\
\text { reduced by } \\
67.7 \% \text { at the } 1- \\
\text { year follow-up } \\
(p<0.001) \text {. }\end{array}$ \\
\hline $\begin{array}{l}\text { Kotilainen et, al. } \\
2001\end{array}$ & $\begin{array}{l}\text { Retrospective } \\
\text { case series } \\
(n=39)\end{array}$ & $\begin{array}{l}\text { Age: } 46.72 \\
\pm 9.78 \\
\text { years-old } \\
\text { Gender: } 23 \\
\text { males vs. } \\
16 \\
\text { females }\end{array}$ & $\begin{array}{l}\text { Microdiscectomy } \\
(n-=25) \text { and } \\
\text { Nucleotomy }(n=14)\end{array}$ & 5 years & $\begin{array}{l}\text { Sciatic pain } \\
\text { completely } \\
\text { recovered or } \\
\text { markedly } \\
\text { diminished } \\
\text { in } 32(82 \%) \\
\text { patients. } \\
\text { Back pain } \\
\text { completely } \\
\text { recovered in } \\
29(74 \%) \\
\text { patients. }\end{array}$ & $\begin{array}{l}\text { Disc } \\
\text { degeneration } \\
\text { was correlated } \\
\text { with } \\
\text { occurrence of } \\
\text { clinical } \\
\text { instability and } \\
\text { post- operative } \\
\text { sick leave. }\end{array}$ \\
\hline
\end{tabular}




\begin{tabular}{|c|c|c|c|c|c|c|}
\hline Author year & Design & Popularion & Intervention & $\begin{array}{l}\text { Follow- } \\
\text { up } \\
\text { period }\end{array}$ & $\begin{array}{l}\text { Clinilcal } \\
\text { outcome }\end{array}$ & $\begin{array}{l}\text { Radiographic } \\
\text { outcome }\end{array}$ \\
\hline $\begin{array}{l}\text { Delamarter et, al. } \\
1995\end{array}$ & $\begin{array}{l}\text { Retrospective } \\
\text { case series } \\
(n=30)\end{array}$ & $\begin{array}{l}\text { Age: } 34 \\
(21-66) \\
\text { years-old } \\
\text { Gender: } 19 \\
\text { males vs. } \\
11 \\
\text { females }\end{array}$ & $\begin{array}{l}\text { Percutaneous } \\
\text { endoscopic } \\
\text { lumbar } \\
\text { discectomy }\end{array}$ & $\begin{array}{l}14 \\
\text { months }\end{array}$ & $\begin{array}{l}17 / 30 \\
\text { patients } \\
\text { complete or } \\
\text { nearly } \\
\text { complete } \\
\text { achieved } \\
\text { pain } \\
\text { resolution in } \\
\text { the back or } \\
\text { lower } \\
\text { extremity or } \\
\text { returned to } \\
\text { work without } \\
\text { medications. }\end{array}$ & $\begin{array}{l}\text { No changes in } \\
\text { the } \\
\text { morphology of } \\
\text { the disc in } \\
24 / 30 \text { patients; } \\
3 / 17 \\
\text { successfully } \\
\text { treated patients } \\
\text { had protrusion } \\
\text { reduction }>2 \\
\text { mm; } \\
2 / 13 \\
\text { unsuccessfully- } \\
\text { treated patients } \\
\text { had increase of } \\
\text { more than } 1 \\
\text { mm of } \\
\text { protrusion. }\end{array}$ \\
\hline
\end{tabular}

Facet joints, together with IVD, comprise a three-joint complex which transfer loads and guide and constrain motions in the spine[16]. Lumbar degenerative changes involves both the IVD and facet joints, and studies have determined that the IVD acts as the initial site of spinal degeneration and that the facet joint degenerates as a result of disc degeneration[17]. Healthy facet joints carry $3-25 \%$ of the axial load; however, the load could be as high as $47 \%$ if in arthritic facet joint[18]. The current population were free of surgically violation of facet joints or facetectomy, hence the imaging follow-ups revealed natural process of degenerative changes of non-instrumented three-joint complex after PETD. Our results indicated that after a minimum follow-up of 2 years, degeneration aggravated at intervertebral but not at facet joints, which is in consistent with previous studies[17]. A finite study by Bashkuev et, al. showed that IVD degeneration have great effect on the facet joint loading at early stages, but facet joint degeneration in turn influences the disc loading with the progress of spine degeneration[19].

The prevalence of facet joint pain is reported to be $27-41 \%$ in the low back area, with a false-positive rate of $25-44 \%$, hence the facet joint pain is underestimated in clinical settings[20]. Regarding postoperative recurrent back pain, the prevalence of facet joint pain could be as high as 16\%[21]. The diagnostic block has been considered as the most validated diagnostic tool, while the management of facet joint pain usually relies on physical therapy and analgesics; however, medial branch blocks, intra-articular injections, radio-frequency denervation or surgeries could be considered if conservative treatment is ineffective[22]. Nonetheless, the distinct relationship between joint degeneration and pain remains as a controversy. In our study, only $1 / 10$ of the patients with facet joint degeneration aggravation manifested back pain symptoms at 3-months follow-up and the last follow-up; however, diagnostic block was not performed on this patient and the combination of oral non-steroidal analgesics and spinal manipulation worked well on the patient, so no surgical intervention was needed.

This study also showed that the size of protrusion significantly decreased in axial MRI cut at last follow-up compare with baseline; however, 10 cases showed radiographic recurrent herniation at the last follow-up. The reherniated disc is not always symptomatic, as the study by Delamarter et, al. documented that the size of herniated disc after surgery reduced only in 3/17 successfully treated patients after a mean follow-up of 14 months[15]. In the present study, most of the patients with radiographic reherniation were asymptomatic (6/11), and only 2 cases required additional surgery at the operated level. The known risk factors for disc herniation recurrence (3.6\%) after PETD are older age, obesity, upper lumbar disc and central disc herniation[23]. However, according to our results, the independent risk factor for radiographic reherniation was facet tropism, a known risk factor of disc degeneration[24]. Facet tropism was defined as a difference of 
more than 10 degrees in facet joint angles between the right and left sides[10]. Our results share similarities with Li et, al.'s findings in which the severity of facet tropism was correlated with risk of reherniation of patients after lumbar spine surgeries for a minimum follow-up of 5 years[25]. It is therefore suggested that evaluation of facet joint morphology to be implemented prior to PETD, in order to better plan for the procedure and inform the patients of potential risks.

The present study has several limitations. Firstly, the retrospective design and the small sample size altogether hindered the reliability of the results. In response, sensitivity analysis validated the robustness of the results. Secondly, we excluded the patients who did not undergo MRI imaging at follow-ups, which could contribute to selection bias because the patients who underwent MRI might be more symptomatic than those who did not. Lastly, we acknowledge that a matching comparison group would increase the strength of this study. Future studies with control group, larger sample size and randomized design are expected to validate our results. Despite these limitations, we believe the findings of our study are sound and generalizable to prove the long-term clinical and radiographic effect of PETD on LDH.

\section{Conclusion}

Taken together, our results demonstrates that despite the satisfying clinical results, the PETD resulted in more degeneration of IVD but not facet joints. The findings should make an important contribution to understanding PETD for both physicians and patients.

\section{Abbreviations}

BMI

Body mass index

IDA

Intervertebral disc angle

IDH

Intervertebral disc height

IVD

intervertebral disc

$\mathrm{LDH}$

Lumbar disc herniation

LL

Lumbar lordosis

MRI

magnetic resonance imaging

MSU

Michigan State University

NRS

Numeric Rating Scale

ODI

Owestry Disability Index

PEID

Percutaneous endoscopic interlaminar discectomy

PETD

Percutaneous endoscopic transforaminal discectomy

\section{Declarations}




\section{Acknowledgements}

Not applicable

\section{Funding}

This study was funded by Interdisciplinary clinical research project of Peking University First Hospital (Grant number: 2021CR31).

\section{Availability of data and materials}

The datasets generated and/or analysed during the current study are not publicly available due privacy or ethical restrictions but are available from the corresponding author on reasonable request.

\section{Ethics approval and consent to participate}

This retrospective study involving human participants was in accordance with the ethical standards of the institutional research committee and with the 1964 Declaration of Helsinki and its later amendments or comparable ethical standards. The Human Investigation Committee (IRB) of Peking University First Hospital approved this study.

All participants in this study were above 18 years of age. The need for written informed consent was waived by the Peking University First Hospital ethics committee due to retrospective nature of the study.

\section{Consent for publication}

All authors read and approved the final manuscript. All authors agree to publish the article.

\section{Competing interests}

The authors declare that they have no competing interests.

\section{Author contributions}

All authors contributed to the study conception and design. Data collection and analysis were performed by $\mathrm{CH}, \mathrm{FH}, \mathrm{MG}$ and LB. The first draft of the manuscript was written by $\mathrm{YL}$ and $\mathrm{SH}$, and all authors commented on previous versions of the manuscript. YL and $\mathrm{CH}$ share the co-first authorship. All authors read and approved the final manuscript.

\section{References}

1. Pan M, Li Q, Li S, et al. Percutaneous Endoscopic Lumbar Discectomy: Indications and Complications. Pain Physician. 2020. 23(1):49-56.

2. Qiao P, Xu T, Zhang W, et al. Foraminoplasty affects the clinical outcomes of discectomy during percutaneous transforaminal endoscopy: a two-year follow-up retrospective study on 64 patients. Int J Neurosci. 2021. 131(1):1-6. http://doi.org/10.1080/00207454.2020.1732968

3. Choi KC, Kim JS, Ryu KS, et al. Percutaneous endoscopic lumbar discectomy for L5-S1 disc herniation: transforaminal versus interlaminar approach. Pain Physician. 2013. 16(6):547-56.

4. Jarman JP, Arpinar VE, Baruah D, et al. Intervertebral disc height loss demonstrates the threshold of major pathological changes during degeneration. Eur Spine J. 2015. 24(9):1944-50. http://doi.org/10.1007/s00586-014$3564-8$ 
5. Mysliwiec LW, Cholewicki J, Winkelpleck MD, et al. MSU classification for herniated lumbar discs on MRI: toward developing objective criteria for surgical selection. Eur Spine J. 2010. 19(7):1087-93. http://doi.org/10.1007/s00586009-1274-4

6. Weishaupt D, Zanetti M, Boos N, et al. MR imaging and CT in osteoarthritis of the lumbar facet joints. Skeletal Radiol. 1999. 28(4):215-9. http://doi.org/10.1007/s002560050503

7. Pfirrmann CW, Metzdorf A, Zanetti M, et al. Magnetic resonance classification of lumbar intervertebral disc degeneration. Spine (Phila Pa 1976). 2001. 26(17):1873-8. http://doi.org/10.1097/00007632-200109010-00011

8. Kettler A, Wilke HJ. Review of existing grading systems for cervical or lumbar disc and facet joint degeneration. Eur Spine J. 2006. 15(6):705-18. http://doi.org/10.1007/s00586-005-0954-y

9. Modic MT, Steinberg PM, Ross JS, et al. Degenerative disk disease: assessment of changes in vertebral body marrow with MR imaging. Radiology. 1988. 166(1 Pt 1):193-9. http://doi.org/10.1148/radiology.166.1.3336678

10. Ishihara $\mathrm{H}$, Matsui $\mathrm{H}$, Osada $\mathrm{R}$, et al. Facet joint asymmetry as a radiologic feature of lumbar intervertebral disc herniation in children and adolescents. Spine (Phila Pa 1976). 1997. 22(17):2001-4.

http://doi.org/10.1097/00007632-199709010-00012

11. Landis JR, Koch GG. The measurement of observer agreement for categorical data. Biometrics. 1977. 33(1):159-74.

12. Lin RH, Chen HC, Pan HC, et al. Efficacy of percutaneous endoscopic lumbar discectomy for pediatric lumbar disc herniation and degeneration on magnetic resonance imaging: case series and literature review. J Int Med Res. 2021. 49(1):300060520986685. http://doi.org/10.1177/0300060520986685

13. Kotilainen E, Alanen A, Erkintalo M, et al. Association between decreased disc signal intensity in preoperative T2weighted MRI and a 5-year outcome after lumbar minimally invasive discectomy. Minim Invasive Neurosurg. 2001. 44(1):31-6. http://doi.org/10.1055/s-2001-13584

14. Mahatthanatrakul A, Kotheeranurak V, Lin GX, et al. Comparative analysis of the intervertebral disc signal and annulus changes between immediate and 1-year postoperative MRI after transforaminal endoscopic lumbar discectomy and annuloplasty. Neuroradiology. 2019. 61(4):411-9. http://doi.org/10.1007/s00234-019-02174-4

15. Delamarter RB, Howard MW, Goldstein T, et al. Percutaneous lumbar discectomy. Preoperative and postoperative magnetic resonance imaging. J Bone Joint Surg Am. 1995. 77(4):578-84. http://doi.org/10.2106/00004623199504000-00011

16. Jaumard NV, Welch WC, Winkelstein BA. Spinal facet joint biomechanics and mechanotransduction in normal, injury and degenerative conditions. J Biomech Eng. 2011. 133(7):071010. http://doi.org/10.1115/1.4004493

17. Faber F. Lumbar facet joint disease: Classification, clinical diagnostics, and minimally invasive treatment. Orthopade. 2019. 48(1):77-83. http://doi.org/10.1007/s00132-018-03667-5

18. Yang KH, King Al. Mechanism of facet load transmission as a hypothesis for low-back pain. Spine (Phila Pa 1976). 1984. 9(6):557-65. http://doi.org/10.1097/00007632-198409000-00005

19. Bashkuev M, Reitmaier S, Schmidt H. Relationship between intervertebral disc and facet joint degeneration: $A$ probabilistic finite element model study. J Biomech. 2020. 102(109518.

http://doi.org/10.1016/j.jbiomech.2019.109518

20. Manchikanti L, Kaye AD, Soin A, et al. Comprehensive Evidence-Based Guidelines for Facet Joint Interventions in the Management of Chronic Spinal Pain: American Society of Interventional Pain Physicians (ASIPP) Guidelines Facet Joint Interventions 2020 Guidelines. Pain Physician. 2020. 23(3s):S1-s127.

21. Manchikanti L, Manchukonda R, Pampati V, et al. Prevalence of facet joint pain in chronic low back pain in postsurgical patients by controlled comparative local anesthetic blocks. Arch Phys Med Rehabil. 2007. 88(4):44955. http://doi.org/10.1016/j.apmr.2007.01.015 
22. O'Leary SA, Paschos NK, Link JM, et al. Facet Joints of the Spine: Structure-Function Relationships, Problems and Treatments, and the Potential for Regeneration. Annu Rev Biomed Eng. 2018. 20(145-70.

http://doi.org/10.1146/annurev-bioeng-062117-120924

23. Yin S, Du H, Yang W, et al. Prevalence of Recurrent Herniation Following Percutaneous Endoscopic Lumbar Discectomy: A Meta-Analysis. Pain Physician. 2018. 21(4):337-50.

24. Alonso F, Kirkpatrick CM, Jeong W, et al. Lumbar Facet Tropism: A Comprehensive Review. World Neurosurg. 2017. 102(91-6. http://doi.org/10.1016/j.wneu.2017.02.114

25. Li Z, Gui G, Zhang Y, et al. Are facet joint parameters risk factors for recurrent lumbar disc herniation? A pilot study in a Chinese population. J Clin Neurosci. 2020. 77(36-40. http://doi.org/10.1016/j.jocn.2020.05.048

\section{Figures}

A

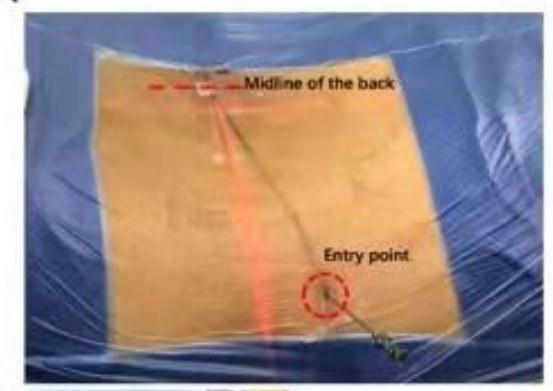

B

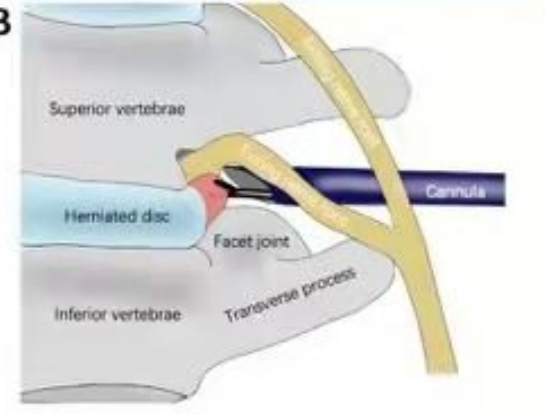

C
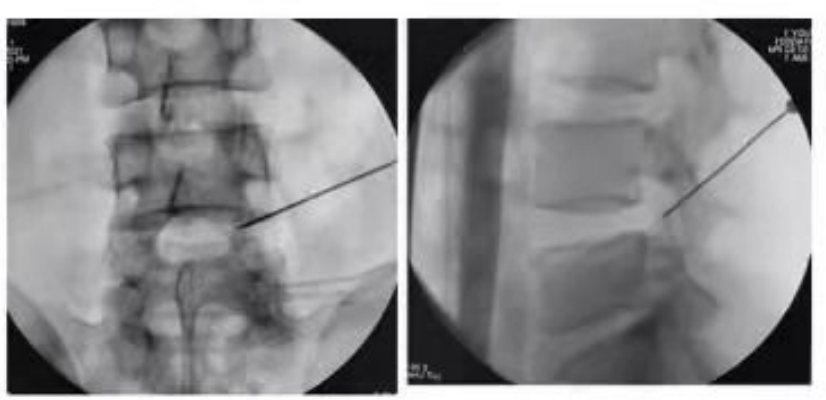

D

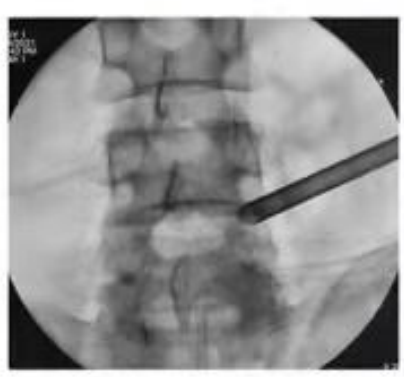

Figure 1

Illustration of PETD procedure. (a) Surgical draping and entry point for L4/5 PETD procedure; (b) Schematic diagram of PETD procedure; (c, d) Puncture needle and working channel introduction under fluoroscopic guidance. 

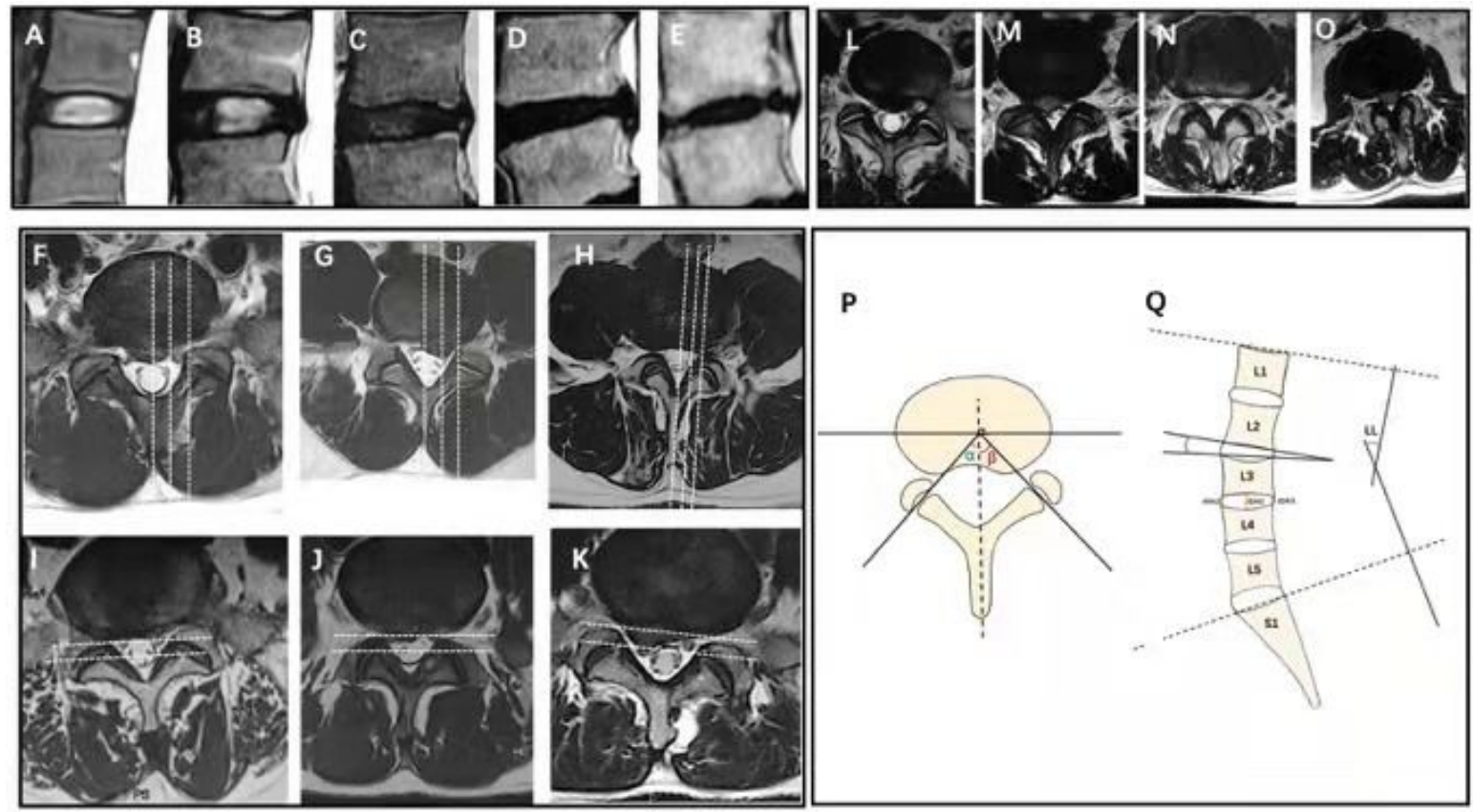

Figure 2

Illustration of radiographic evaluations. (A-E) Pfirrmann grading for intervertebral disc degeneration: grade I, grade II, grade III, grade IV, and grade V, respectively; $(\mathrm{F}-\mathrm{H}) \mathrm{MSU}$ grading for the location of herniated disc: grade $\mathrm{A}$ (herniation coronally < 50\% mid-to-intra-facet-line), B (herniation coronally 50\%-100\% mid-to-intra-facet-line), and C (herniation coronally over intra-facet line); (I-L) MSU grading for the size of herniated disc: grade 1 (sagittal herniation < 50\% mid-tointra-facet-line), grade 2 (sagittal herniation 50\%-100\% mid-to-intra-facet-line), grade 3 (sagittal herniation over intra-facet line); (L-O) Weishaupt grading systems for degeneration of facet joint: grade 0 (normal FJS of 2-4 mm), grade 1 (narrowing of the FJS/small osteophytes/mild APH), grade 2 (narrowing of the FJS/moderate osteophytes/moderate $\mathrm{APH} / \mathrm{mild} \mathrm{SBE}$ ), and grade 3 (narrowing of the FJS/large osteophytes/severe APH/severe SBE). (P) Facet tropism is determined by the difference over 10 degrees between angle $a$ and angle $\beta$; $(\mathrm{Q})$ Disc height $(\mathrm{mm})$ is the average value of height at the anterior (IDH1), middle (IDH2), and posterior (IDH3) height of interverbal disc; and LL is the angle between the superior edge of L1 vertebrae and S1 vertebrae; and IDA is the angle between the adjacent endplates of the intervertebral space. Abbreviations: $\mathrm{APH}=$ articular process hypertrophy, FJS = facet joint space, IDH = intervertebral disc height, IDA = intervertebral disc angle, LL = lumbar lordosis, SBE = subarticular bone erosions 
A

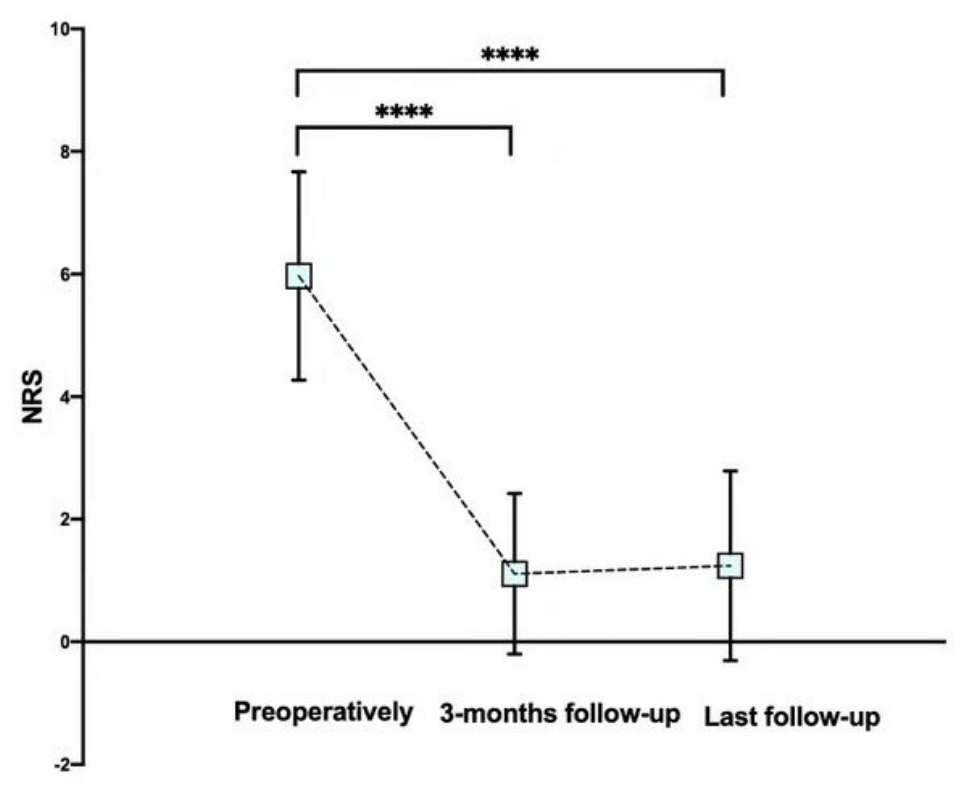

B

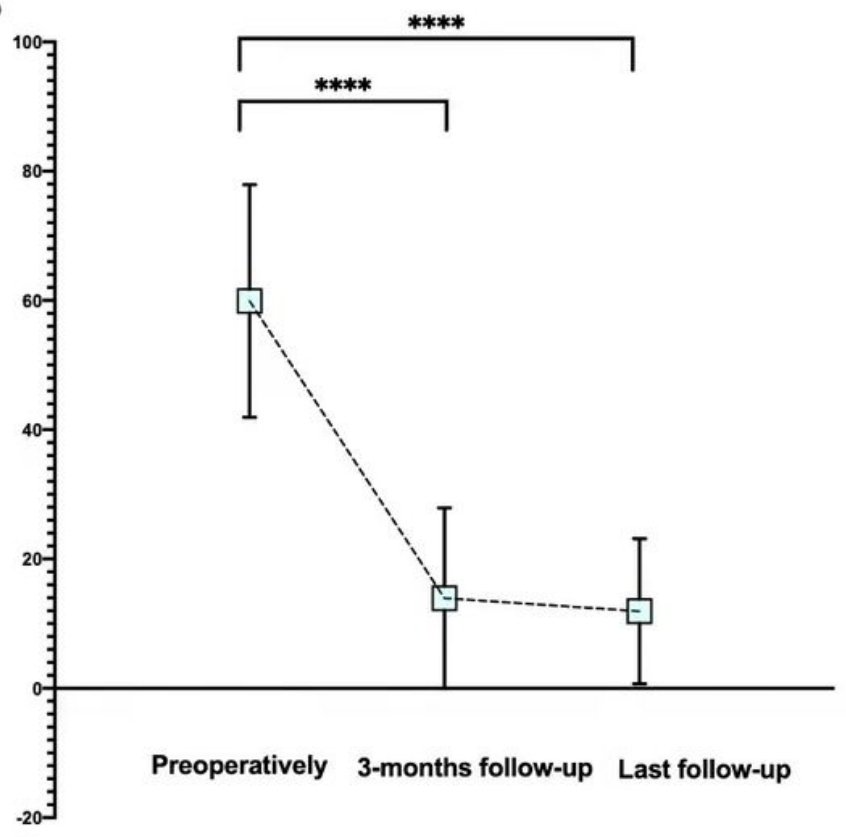

Figure 3

Change in postoperative patient-reported outcome (a. NRS score and b. ODI score). Error bars are $95 \%$ confidence intervals. **** $p<.0 .0001$.
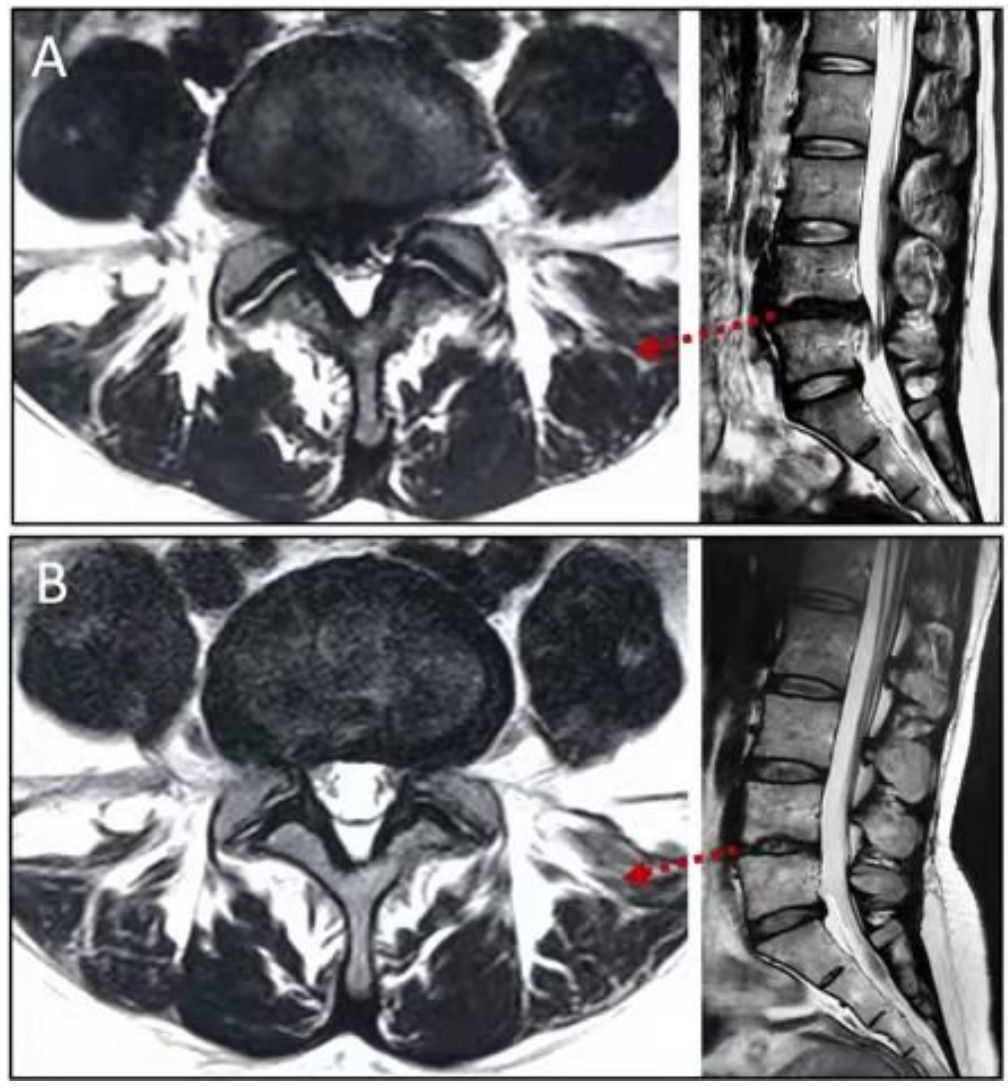

Figure 4 
One of our cases. 38-year-old female with low-back pain and sciatica for 6 months. (A) Preoperative MRI showed lesion type 2-A according to MSU classification, and the Pfirrmann grading was IV and the Weishaupt grading was 0 . No sign of facet tropism or Modic change was noticed. Her baseline NRS was 5 and ODI was 46.67\%; (B) MRI images of 25 months after surgery. MRI showed no residual herniation. The Pfirrmann grading was V, and the Weishaupt grade was grade 1 . At the last follow-up the patient reported satisfying results with NRS of 0 and ODI of $15.56 \%$. 